\title{
Erratum to: Interrelations between soil respiration and its thermal stability
}

\author{
Christian Siewert • Michael Scott Demyan • \\ Jiří Kučerík
}

Published online: 1 June 2012

(C) Akadémiai Kiadó, Budapest, Hungary 2012

\section{Erratum to: J Therm Anal Calorim \\ DOI 10.1007/s10973-011-2099-z}

The authors would like to add the below Acknowledgements to the original publication of the article.

Acknowledgements The authors would like to thank Mr. Jiří Kislinger for sample collection and good laboratory work.

The online version of the original article can be found under doi:10.1007/s10973-011-2099-z.

\section{Siewert}

Faculty of Landscape Management, University of Applied Sciences Dresden, Pillnitzer Platz 2, 01326 Dresden, Germany

e-mail: cs@csiewert.de

\section{S. Demyan}

Institute of Plant Production and Agroecology in the Tropics and Subtropics, University of Hohenheim, Garbenstrasse 13, 70593 Stuttgart, Germany

e-mail: scott_demyan@yahoo.com

J. Kučerík

Faculty of Chemistry, Brno University of Technology,

Purkyňova 118, 61200 Brno, Czech Republic

J. Kučerík (ه)

Institute of Environmental Sciences, University of Koblenz-

Landau, Fortstrasse 7, 76829 Landau, Germany

e-mail: kucerik@uni-landau.de 